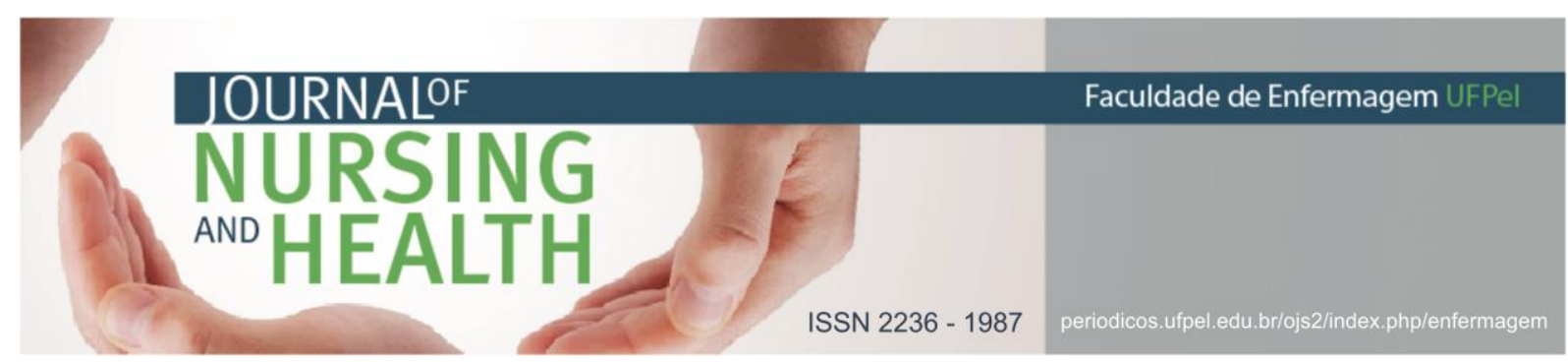

DEPOIMENTOS DOS EXPERTS POR EXPERIÊNCIA

\title{
Um desafio cotidiano: aprender a conviver com as vozes
}

\author{
A daily challenge: learn to live with the voices
}

Un desafío cotidiano: aprender a convivir con las voces

Bender, Andrea Regina Molina Jaekel ${ }^{1}$; Tavares, Diogo Henrique ${ }^{2}$; Coradini, Djeniffer Rodrigues ${ }^{3}$; Lopes, Ivon Fernandes ${ }^{4}$; Farias, Izamir Duarte ${ }^{5}$; Silva, Larissa Dall’ Agnol da ${ }^{6}$; Ubessi, Liamara Denise $^{7}$; Silveira, Priscila Borges ${ }^{8}$

Como citar este artigo: Bender ARMJ, Tavares DH, Coradini DR, Lopes IF, Farias ID, Silva LD, et al. Um desafio cotidiano: aprender a conviver com as vozes. J. nurs. health. 2018;8(n.esp.):e188410

Palavras-chave: Saúde mental; Terapêuticas; Ouvidores de vozes.

\section{APRESENTAÇÃO}

Historicamente o tratamento em saúde mental é pautado em reclusão e afastamento da sociedade e da família, prática aceita e sustentada pelo preconceito e "patologização" do sujeito. Nesse sentido, Foucault, um dos principais ícones da filosofia contemporânea, aponta com propriedade para uma organização perversa de uma sociedade que reprime e não comporta diferenças. ${ }^{1,2}$

Para tanto, utiliza-se de métodos nefastos e uma instrumentalização que busca moldar ou "docilizar os corpos", ao que podemos chamar de instituição manicomial, apoiada por poderes instituídos por corpus jurídicos, médicos, políticos, militares e a grande indústria farmacêutica. ${ }^{1-2}$

\footnotetext{
${ }^{1}$ Agricultora e artesã. Usuária do Centro de Atenção Psicossocial. Integrante da Associação de Usuários(as) dos Serviços de Saúde Mental de Pelotas (AUMSSPE). E-mail: andreabender52@gmail.com - https://orcid.org/00000001-8622-503

2 Enfermeiro. Mestre em Ciências. Universidade Federal de Pelotas (UFPEL). E-mail: enf.diogotavares@gmail.com - http: //orcid.org/0000-0002-0961-6421

3 Psicóloga. Coordenadora Regional das Políticas de Equidade em Saúde: Saúde da População Negra, Povos Indígena, População de Lésbicas, Gays, Bissexuais, Travestis e Transexuais (LGBT) e Saúde Prisional da Terceira Coordenadoria Regional de Saúde do Rio Grande do Sul. E-mail:djeniffercoradini@gmail.com https: / /orcid.org/0000-0002-5219-9037

${ }^{4}$ Acadêmico de Serviço Social pela Universidade Católica de Pelotas (UCPEL). Presidente da Associação de Usuários (as) dos Serviços de Saúde Mental de Pelotas (AUSSMPE). E-mail: ivonlopesnaval@hotmail.com https: / / orcid.org/0000-0003-3182-9113

${ }^{5}$ Licenciado em Artes e Habilitado em Música Pela UFPEL. Mestre e Doutor em Ciências. Prefeitura Municipal de Pelotas. E-mail: izamironline@hotmail.com - https://orcid.org/0000-0001-7289-8284

6 Terapeuta Ocupacional. Universidade Federal de Pelotas (UFPEL). E-mail:larissadallagnolto@gmail.com https://orcid.org/0000-0002-5627-7442

7 Graduada em Psicologia e Enfermagem. Doutora em Ciências. Universidade Federal de Pelotas (UFPEL). E-mail: liaubessi@gmail.com https: //orcid.org/0000-0002-5884-9969

${ }^{8}$ Educadora Física. Especialista em Saúde Coletiva e Saúde Mental. Prefeitura Municipal de Pelotas. E-mail: prisborges.prof@gmail.com http://orcid.org/0000-0001-7148-4186
} 


\section{NURSING \\ AND \\ HEALTH \\ ISSN $2236-1987$}

Nos dias atuais, a partir da Portaria Ministerial n 3.588 de dezembro de 2017, - Brasil declina na luta travada pela Luta Antimanicomial e reforma psiquiátrica ao reinstituir os antigos manicômios e agregá-los à Rede de Atenção Psicossocial (RAPS), em vez de instrumentalizar hospitais gerais para internação em saúde mental (quando justifica-se).

$\mathrm{Na}$ cidade de Pelotas, onde existem oito Centros de Atenção Psicossocial (CAPS) e diversas estratégias para um cuidado em liberdade, no ano da referida portaria que fortalece os manicômios, surge um importante relato de vivências, afetações e marcas na alma de uma cidadã que esteve no manicômio, o qual ainda insiste em coexistir e restringir liberdades.

Nesta perspectiva, o relato de Andrea Regina Molina Jaekel Bender possui importante teor para contrapor tal modificação na política que repercute na redução de investimentos voltados aos leitos em hospitais gerais com vistas a cuidar da pessoa na sua integralidade, bem como a todas as estratégias para cuidado em liberdade e para empoderamento do sujeito humano.

Falar de cuidado e liberdade está diretamente relacionado com a compreensão das diferenças e respeito às potencialidades e singularidade de cada sujeito.

Andrea Regina Molina Jaekel Bender já narrou sua história de vida e experiência com as vozes em reuniões e assembleias da Associação de Usuários(as) dos Serviços de Saúde Mental de Pelotas (AUSSMPE) e no Centro de Atenção Psicossocial (CAPS) Escola. Em meio a esses espaços lotados, a autora verbalizou com firmeza e emoção suas experiências, as quais emocionaram as pessoas que a ouviam, seja integrantes da Associação e assistidas na Atenção Psicossocial, trabalhadores(as), familiares, entre outros(as).

Do mesmo modo, essas narrativas remontaram memórias de pessoas que também vivenciaram tais sofrimentos. Tudo por conta da "patologização" da pessoa que possui uma percepção diferenciada, como ouvir vozes que outros (as) não ouvem. A eternização da presente narrativa é resistência diante de perdas que nós todos(as), cidadãos e cidadãs brasileiros(as) vimos enfrentando no âmbito das liberdades. mesma!

Eis então, a narrativa de Andrea Regina Molina Jaekel Bender. Ela por ela

\section{Vou me apresentar!}

Me chamo Andrea Regina Molina Jaekel Bender, sou agricultora, artesã, ouvidora de voz desde criança, usuária do CAPS Escola há 12 anos, integrante da AUMSSPE.

\section{Encontro com a vozes na infância: perplexidade entre mente e espiritualidade}

Desde criança, lembro de ouvir vozes, antes de entrar para escola. Nesse tempo crianças brincavam e falavam comigo, com o tempo ouvia ruídos, sons de 
gritos, choro, respiração forte, como alguém com falta de ar e por vezes xingamentos e som como um rádio mal sintonizado. Na maioria do tempo, vem do nada posso estar lendo, conversando ou até andando na rua.

Não sei explicar, já fui quando criança benzida, fui ao centro espírita, um dos locais que me ajuda a conviver com elas. Mas acredito que não seja algo espiritual, mas remédios também não ajudam muito. Acho que minha mente as produz e ao mesmo tempo acho que é algo externo no qual não tenho controle, muitas vezes sinto a presença de alguém próximo de mim, algo quase físico, mas intocável.

'Elas ali estão à maioria do tempo' - medos, dificuldades, aprendizados e estratégias

Lido hoje com menos medo de falar sobre o assunto, com outras pessoas, menos receio, mas sempre deixo escapar alguma coisa sobre o assunto. Tento passar o tempo com a mente ocupada para não ouvir, pois elas ali estão a maioria do tempo. Quando estou triste fica difícil, elas sussurram e me induzem as coisas que não controlo, até a tentar suicídio. Elas nesse momento manipulam, contra pessoas que amo, até fazer com que ofenda.

Quando mais nova, muitas vezes, tinha muita raiva, tinha ordens para agredir, atirar facas nas minhas irmãs. Hoje controlo muito, essa reação de agredir fisicamente alguém, mas elas têm poder de me diminuir, fazer que eu me sinta inútil ao ponto de chegar quase ao extremo, contra a minha vida.

Tenho medo de um dia não controlar mais, não disfarçar quando estou ouvindo, de não ter alguém que esteja ao meu lado, quando o extremo chega e fazer algo que na verdade fui induzida a fazer, talvez, pela voz da minha própria mente. Eu acredito que só falando, informando-se, convivendo com outros ouvidores, trocando experiências já vividas e saber que não é único. Sugiro mais conversas e menos medicação.

\section{'Fico muito feliz de poder abrir um pouco do meu coração' - o encontro} com o movimento de ouvidores(as) de vozes

Acho que têm pessoas que tem um dom espiritual, outros problemas graves mentais e isso a psiquiatria comprova e outros que são como eu, ouvem, mas convivem uma vida toda, tem crises, mas é da sua natureza, nasceu com as vozes, mas pode produzir, estudar, ter família e viver em sociedade como qualquer pessoa. Só precisa se conhecer e saber como achar a melhor maneira de não ser comandado por elas.

Descobri o movimento quando ouvi falar de Mário Cardano e que na minha cidade tinham pessoas que viam como algo mais natural, não como uma demência, fui pesquisar sobre o assunto e ver vídeos na internet. Isso me 


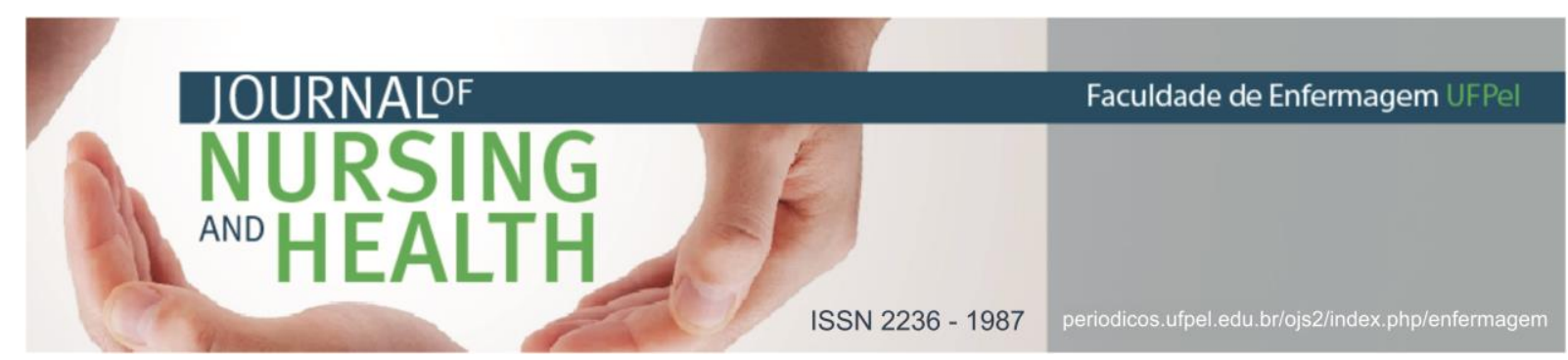

ajudou muito a falar até para os profissionais que me tratam. Não falava por medo de ser internada e enlouquecer de vez, mas fiquei mais segura para falar sobre, até com meus filhos.

Gostaria de dizer que não somos os únicos, em alguns casos como o meu, somos produtivos! Temos que nos ajudar, o silêncio corrói por dentro, e esse silêncio, o medo de falar, o medo de enfrentar as vozes, só vai ter paz com ajuda, com compreensão e não com cargas de medicação. O ouvidor nem sempre é um doente, não é louco, só tem algo diferente e temos que lidar e aceitar as diferenças. As vozes existem, mas alguém pode parar de sofrer se for aceito e ajudado, para conviver com elas!

Fico muito feliz de poder abrir um pouco do meu coração. Obrigada Lia, que Deus te ilumine, pois essas perguntas me deixaram mais leve e sei que vai entender de outro ponto de vista. Isso é só um pingo de tudo que passo, só com sons, que só eu ouço, vozes que só eu escuto.

\section{A possibilidade de produção de vida}

No contexto, valoramos a essência a construção do percurso da depoente. A narradora Andrea Regina Molina Jaekel Bender, representa no contexto da atualidade a vida que segue, autora da sua produção de vida e também a realidade possível do cuidado em liberdade. Nesse sentido, as conquistas históricas das mudanças nas políticas públicas de saúde e assistência, compromete-se com a vida das pessoas em seus cotidianos e territórios.

Assim, marcamos resistência em defesa da Reforma Antimanicomial, da atenção psicossocial e em redes, do cuidado em liberdade e do Sistema Único de Saúde para garantir a vida das pessoas. Saudamos os ouvintes, depoentes, transcritores e o coletivo responsável pelo registro e memória desta narrativa.

\section{REFERÊNCIAS}

1 Foucault M. Os corpos dóceis. In: Foucault M. Vigiar e punir: nascimento da prisão. $29^{\mathrm{a}}$ ed. Tradução de Raquel Ramalhete. Petrópolis: Vozes; 2004, p. 125-52.

2 Foucault M. A ordem do discurso. São Paulo: Loyola; 1996.

Data de publicação: 19/09/2018 